\title{
PENDUGAAN DAMPAK PENCEMARAN TRIBUTYLTIN MENGGUNAKAN GEJALA IMPOSEKS PADA GASTROPODA DI PERAIRAN BITUNG, SULAWESI UTARA
}

\author{
(The Estimation of Pollution Impact of Tributyltin Using The Symptoms of Imposex In \\ Gastropod In The Waters Of Bitung, North Sulawesi)
}

Rofenly Mamonto ${ }^{1}$, Natalie D. Rumampuk ${ }^{1}$, Markus T. Lasut ${ }^{1^{\star}}$

1. Program Studi IImu Kelautan, Fakultas Perikanan dan IImu Kelautan, Universitas Sam Ratulangi, Manado.

*e-mail : markus_lasut@yahoo.com

The waters of Bitung, North Sulawesi, has shipping activity that allows these waters contaminated with pollutants tributyltin compounds. Therefore, it is necessary to investigate and detect symptoms imposex TBT content in the body of gastropods. Types of gastropods are taken as the test material is gastropods kind Thais aculeata, Monodonta labio, and Nerita exuvia. Imposex observations on gastropods generally done with surgery to see the genital organs that occurs. Sexual determination is done by observing the presence of sperm-ingesting gland or prostate gland that exist only on the individual male and staining the gonads. Imposex symptoms on gastropods $T$. aculeata, $M$. labio, and $N$. exuvia taken from the waters of Bitung has imposex level is high enough. Of the results showed symptoms was highest in gastropods imposeks $T$. aculeata types, gastropods which is also easily found in the area of the research sites. Based on the results of this study concluded that the phenomenon imposex spread fairly high in the study area to an average value RPLI ranging from $58.5 \%-80.67 \%$.

Keyword: Thais aculeata, Monodonta labio, Nerita exuvia, Tributyltin

Perairan Bitung, Sulawesi Utara, memiliki aktifitas perkapalan yang memungkinkan perairan tersebut terkontaminasi dengan polutan senyawa tributyltin. Oleh karena itu, perlu dilakukan penelitian untuk mengetahui gejala imposeks dan mendeteksi kandungan TBT dalam tubuh gastropoda. Jenis gastropoda yang diambil sebagai bahan uji adalah gastropoda jenis Thais aculeata, Monodonta labio, dan Nerita exuvia. Pengamatan imposeks pada gastropoda umumnya dilakukan dengan pembedahan untuk melihat organ kelamin yang terjadi. Determinasi seksual dilakukan dengan mengamati keberadaan sperm-ingesting gland atau kelenjar prostat yang hanya ada pada individu jantan serta pewarnaan pada gonad. Gejala imposeks pada gastropoda $T$. aculeata, M. labio, N. exuvia yang diambil dari Perairan Bitung memiliki tingkat imposeks cukup tinggi. Dari hasil penelitian menunjukkan gejala imposeks tertinggi terjadi pada gastropoda jenis $T$. aculeata, dimana gastropoda ini juga mudah ditemukan di area lokasi penelitian. Berdasarkan hasil penelitian dapat disimpulkan bahwa fenomena imposeks menyebar cukup tinggi di wilayah studi dengan nilai rerata RPLI berkisar $58.5 \%-80.67 \%$.

Kata Kunci: Thais aculeata, Monodonta labio, Nerita exuvia, Tributyltin

\section{PENDAHULUAN}

Aktifitas perekonomian yang dilakukan di kawasan pesisir, diantaranya, yaitu kegiatan transportasi laut, pelabuhan perikanan (tangkap dan budidaya), industri, dan pariwisata. Menurut Rompas (1994), hasil dari aktivitas manusia, sebagai tanda adanya kemajuan teknologi dalam bidang industri, pertambangan, transportasi laut dan sebagainya dapat mengakibatkan munculnya beraneka ragam zat dan bahan yang berbahaya bagi lingkungan hidup dimana pada akhirnya dapat merusak lingkungan, termasuk organisme yang hidup di 
dalamnya. Salah satu contoh kerusakan lingkungan yang sedang terjadi, yaitu munculnya gejala imposeks (perkembangan organ kelamin jantan pada individu betina) pada organisme gastropoda laut (Smith 1971 dalam Andersen et al., 2004).

Gejala imposeks yang merupakan gangguan pada sistem reproduksi pada organisme gastropoda laut telah diketahui disebabkan oleh akumulasi senyawa kimia tributyltin (TBT); oleh karena itu, hal ini telah menjadi salah satu indikator utama dari aspek biologi akan tercemarnya suatu perairan oleh TBT (Sudaryanto, 2001). Pengamatan imposeks pada moluska umumnya dilakukan dengan pembedahan untuk melihat organ kelamin yang terjadi. Determinasi seksual dilakukan dengan mengamati keberadaan sperm-ingesting gland atau kelenjar prostat yang hanya ada pada individu jantan serta pewarnaan pada gonadnya (Svavarsson, 2000).

Seperti halnya perairan laut secara umum, perairan laut di Bitung rentan terhadap pencemaran TBT sehingga kekhawatiran akan terjadinya dampak kerusakan lingkungan yang disebabkan oleh senyawa tersebut, seperti imposeks diduga telah terjadi. Untuk itu, perlu diadakan penelitian untuk mengetahui gejala imposeks dan mendeteksi kandungan TBT dalam tubuh gastropoda.

\section{METODOLOGI PENELITIAN}

Pengambilan sampel dilakukan di dua lokasi yaitu perairan Pelabuhan Bitung dan perairan Pelabuhan Samudra. Pada daerah pengambilan sampel di Perairan Bitung, yaitu pada daerah pelabuhan akan ditandai berdasarkan titik koordinat menggunakan Global Positioning System (GPS). Hal ini dilakukan untuk memungkinkan dilakukan pengulangan dimasa yang akan datang.

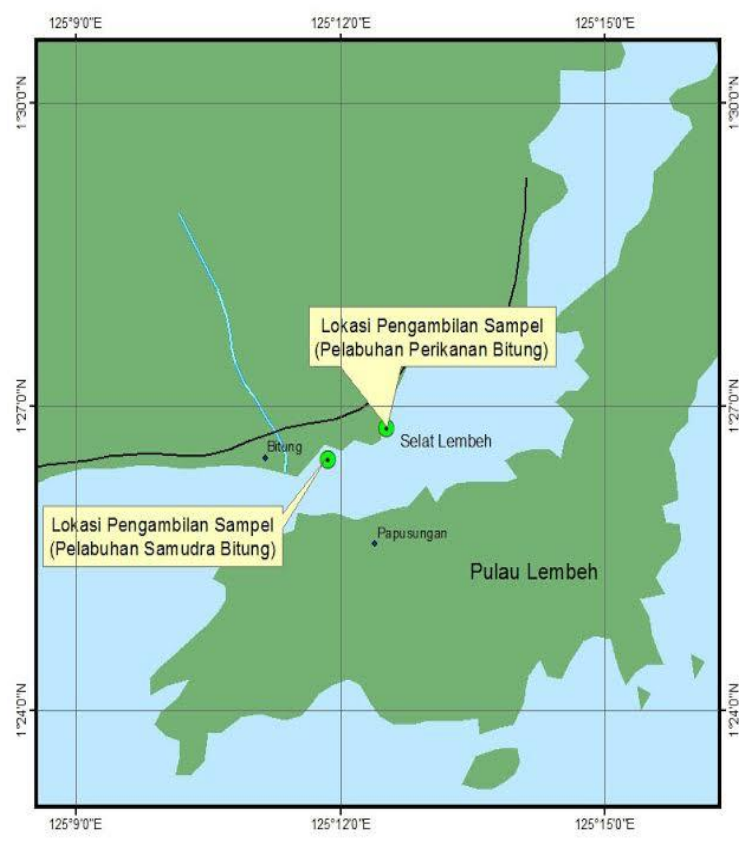

Gambar 1. Lokasi pengambilan sampel di Perairan Bitung

Pengambilan sampel dilakukan pada siang hari, pada saat air surut, dengan menggunakan teknik survei jelajah. Sampel gastropoda (Thais aculeata, Monodonta labio, Nerita exuvia) di ambil menggunakan tangan masing-masing 30 individu pada setiap lokasi kemudian dikumpulkan dan dimasukkan ke dalam ember yang telah berisi air laut. Hal ini dilakukan untuk menjaga sampel tetap dalam keadaan hidup ketika dibawa ke laboratorium untuk dilakukan pengamatan.

Untuk pengamatan imposeks, terlebih dahulu sampel dibius dengan cara mencelupkannya ke dalam larutan $\mathrm{MgCl} 2$. Hal ini dilakukan untuk menjamin supaya bagian lunak organisme yang diamati dalam keadaan baik dan siap untuk diamati. Kemudian, cangkang dipecahkan menggunakan martil dan tubuh gastropoda diletakkan pada cawan petri selanjutnya dilakukan pemeriksaan gejala imposeks. Pengamatan dilakukan dengan menggunakan lup. Sampel yang menunjukkan karakter imposeks diamati dengan melihat ada tidaknya penis yang berada di bagian belakang tentakel. Panjang penis 
individu jantan dan individu imposeks diukur menggunakan kaliper. Setelah pengukuran selesai, dilanjutkan dengan menghitung tingkat imposeks. Individu yang mengalami imposeks dari betina, dapat disimpulkan memiliki pseudopenis dan atau vas deferens (Widianwari, 2010).

Evaluasi gejala imposeks ditentukan dengan menghitung parameter Indeks Relatif Panjang Penis. Parameter tersebut dihitung menggunakan rumus sebagai berikut: Indeks Relatif Panjang Penis (Relative Penis Length Indeks/RPLI):

RPLI

$=\frac{(\text { rerata panjang penis pada betina })}{(\text { rerata panjang penis jantan })} \times 100 \%$

\section{HASIL DAN PEMBAHASAN}

Hasil

pengamatan

menunjukkan, bahwa kasus perubahan kelamin (imposeks) pada gastropoda ( $T$. aculeata) yang dikumpulkan di Pelabuhan Perikanan dan Pelabuhan Samudera Bitung dengan hasil pengukuran penis gastropoda normal adalah sebesar 3,2 - 3,34 mm, sedangkan pada betina yang menunjukkan karakter imposeks adalah sebesar 2,55 - 2,75 $\mathrm{mm}$ dengan persentase rerata nilai RPLI sebesar $80,67 \%$ (Tabel 1). Pada jenis gastropoda $M$. labio dan $N$. exuvia hanya di temukan di sekitar Pelabuhan Perikanan dan tidak di jumpai di Pelabuhan Samudera. Pada gastropoda jenis $M$. labio, yang di dapat di Pelabuhan Perikanan, rerata ukuran penis jantan normal adalah $3,75 \mathrm{~mm}$ dan rerata ukuran penis betina imposeks adalah 2,17 $\mathrm{mm}$ dengan persentase nilai RPLI sebesar 58,4 \% (Tabel 2). Untuk jenis gastropoda $N$. exuvia, persentase nilai rerata ukuran penis jantan normal, di Pelabuhan
Perikanan, adalah sebesar 3,63 $\mathrm{mm}$. Sedangkan rerata panjang penis pada betina imposeks sebesar 2,21 $\mathrm{mm}$ dengan nilai persentase RPLI sebesar $60,88 \%$ (Tabel 3).

Berdasarkan hasil analisis terhadap organ reporoduksi jantan dan betina dari ketiga spesies gastropoda ini mengindikasikan terjadinya gejala imposeks dengan nilai tertinggi terjadi pada spesies gastropoda jenis $T$. aculeata dengan nilai imposeks tertinggi mencapai 80,67 \%. Gejala imposeks yang terjadi di Perairan Bitung ini nampak jauh lebih rendah dengan hasil yang di peroleh dari penelitian di perairan Bitung sebelumnya yang dilakukan oleh Noor et al., (2013) dengan menggunakan sampel gastropoda Thais tuberosa dengan kisaran nilai imposeks tertinggi sebesar $60 \%$ dan gastropoda M. labio sebesar $44 \%$. Perbandingan dari kedua hasil ini menunjukkan gejala imposeks yang terjadi di Perairan Bitung semakin meningkat dengan adanya aktivitas perkapalan yang ramai.

Castro et al., (2007) mengemukakan fenomena imposeks akibat senyawa TBT umumnya terjadi pada daerah di mana laju kegiatan transportasi laut maupun industri yang tinggi seperti di pelabuhan dan dok kapal, sedangkan pada daerah pantai yang dilindungi dengan tingkat arus transportasi yang rendah memiliki frekuensi imposeks yang rendah (Kirli, 2005 dalam Islami, 2011).

Tinjauan kejadian imposeks di wilayah Asia Tenggara telah dilakukan pada tahun 1988 dan 1989 yang meliputi Indonesia, Malaysia dan Singapura. Seperti jenis gastropoda Thais luteustoma yang ditemukan di Teluk Ambon, Indonesia, telah mengalami 
Tabel 1. Perbandingan Persentase RPLI (\%) T. aculeata Jantan dan Betina yang menunjukkan karakter Imposeks berdasarkan Lokasi di Perairan Bitung.

\begin{tabular}{|c|c|c|c|c|c|c|}
\hline LOKASI & Posisi Geografi & $\begin{array}{c}\text { Titik } \\
\text { Pengambilan }\end{array}$ & $\begin{array}{c}\text { Rerata } \\
\text { Ukuran Penis } \\
\text { Jantan } \\
\text { Normal }(\mathrm{mm})\end{array}$ & $\begin{array}{c}\text { Rerata } \\
\text { Ukuran Penis } \\
\text { Pada Betina } \\
\text { Imposeks }(n)\end{array}$ & RPLI (\%) & $\begin{array}{c}\text { Rerata } \\
\text { RPLI } \\
(\%)\end{array}$ \\
\hline \multirow{2}{*}{$\begin{array}{c}\text { Perairan } \\
\text { Bitung }\end{array}$} & 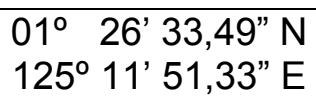 & $\begin{array}{l}\text { Pelabuhan } \\
\text { Samudra }\end{array}$ & 3,2 & 2,72 & 85 & \multirow{2}{*}{80,67} \\
\hline & 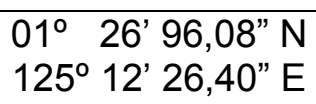 & $\begin{array}{l}\text { Pelabuhan } \\
\text { Perikanan }\end{array}$ & 3,34 & 2,55 & 76,35 & \\
\hline
\end{tabular}

Tabel 2. Perbandingan Persentase RPLI (\%) M. labio Jantan dan Betina yang menunjukkan karakter Imposeks berdasarkan Lokasi di Perairan Bitung.

\begin{tabular}{|c|c|c|c|c|c|}
\hline LOKASI & Posisi Geografi & $\begin{array}{c}\text { Titik } \\
\text { Pengambilan }\end{array}$ & $\begin{array}{c}\text { Rerata } \\
\text { Ukuran Penis } \\
\text { Jantan } \\
\text { Normal (mm) }\end{array}$ & $\begin{array}{c}\text { Rerata } \\
\text { Ukuran Penis } \\
\text { Pada Betina } \\
\text { Imposeks (n) }\end{array}$ & RPLI (\%) \\
\hline $\begin{array}{l}\text { Perairan } \\
\text { Bitung }\end{array}$ & 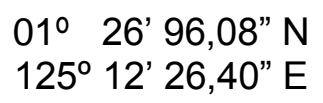 & $\begin{array}{l}\text { Pelabuhan } \\
\text { Perikanan }\end{array}$ & 3,75 & 2,19 & 58,4 \\
\hline
\end{tabular}

Tabel 3. Perbandingan Persentase RPLI (\%) N. exuvia Jantan dan Betina yang menunjukkan karakter Imposeks berdasarkan Lokasi di Perairan Bitung.

\begin{tabular}{cccccc}
\hline & & Titik & $\begin{array}{c}\text { Rerata } \\
\text { Ukuran Penis } \\
\text { Jantan } \\
\text { Lormal (mm) }\end{array}$ & $\begin{array}{c}\text { Rerata } \\
\text { Ukuran Penis } \\
\text { Pada Betina } \\
\text { Imposeks (n) }\end{array}$ & RPLI (\%) \\
\hline $\begin{array}{c}\text { Perairan } \\
\text { Bitung }\end{array}$ & $\begin{array}{l}01^{\circ} \\
125^{\circ} 16^{\prime}, 96,08^{\prime \prime} \text { N } 26,40^{\prime \prime} \mathrm{E}\end{array}$ & $\begin{array}{c}\text { Pelabuhan } \\
\text { Perikanan }\end{array}$ & 3,63 & 2,21 & 60,88 \\
\hline
\end{tabular}

imposeks sebesar $30-100 \%$ (Ellis dan Pattisina, 1990). Pandey dan Evans (1996) melaporkan bahwa nilai imposeks pada gastropoda jenis Morula granulata dewasa asal Pelabuhan Manado adalah sebesar $85 \%$ dan jenis Thais sp. dewasa asal Pelabuhan Bitung adalah sebesar $75 \%$, sementara penelitian yang dilakukan oleh Wagiman, (2004), di pelabuhan Dickson, Malaysia, frekuensi imposeks tertinggi terjadi pada gastropoda Thais luteustoma adalah sebesar $100 \%$ dan dari hasil penelitian yang di proleh dalam studi yang dilakukan oleh Yusuff et al., (2011) pada semua individu Thais tuberosa dari Semenanjung Malaysia, di Pantai Penang Royal 
Custom dan Teluk Senangan, juga mempunyai gejala imposeks mencapai $100 \%$.

Dari beberapa kajian penelitian menunjukkan, bahwa gejala imposeks yang terjadi di Perairan Bitung, di Pelabuhan Samudera dan di Pelabuhan Perikanan memperlihatkan hasil yang hampir tidak jauh berbeda dengan nilai gejala imposeks yang terjadi di negara-negara Eropa, Amerika maupun di negara Asia Tenggara lainnya. Goldberg (1986) menyatakan bahwa pada tahun 1970an terbukti bahwa TBT merupakan bahan yang paling toksik yang pernah terlepas ke dalam perairan laut. Namun masih banyak ruang penelitian yang dilakukan lagi untuk mengindikasikan tentang adanya faktor-faktor lain yang mungkin membantu perubahan rasio gender dalam populasi gastropoda. Informasi yang diperoleh juga dapat dijadikan dasar untuk perbandingan penelitian yang akan datang dan memperbaharui data yang telah ada.

\section{KESIMPULAN}

Gejala imposeks pada gastropoda $T$. aculeata, M. labio, dan N. exuvia dari Perairan Bitung memiliki tingkat imposeks cukup tinggi. Tingkat imposeks tertinggi terjadi pada gastropoda jenis $T$. aculeata $80.67 \%$.

Fenomena imposeks menyebar cukup tinggi di wilayah studi dengan nilai rerata Imposeks mencapai 66.66 $\%$ - $84.61 \%$. Dari jenis gastropoda yang di ambil, betina yang terkena imposeks memiliki nilai rerata RPLI berkisar $58.5 \%-80.67 \%$.

\section{DAFTAR PUSTAKA}

Andersen, L. E. 2004. Imposex: A Biological Effect of TBT Contamination in Port Curtis, Queensland. Australia Journal Ecotoxicology. 10: 105-113.
Castro, I. B., Lima, A. F. A., Braga, A. R. C., Barreira, C. A. 2007. Imposex in Two Muricid Species (Mollusca; Gastropoda) From The Northeastern Brazillian Coast. Journal of The Brazillian Society of Ecotoxicology, 2(1), pp. 81-91.

Ellis, D., V., Pattisina, A. 1990. Widespread Neogastropoda Imposex: A Biological Indicator of Global TBT Contamination? Marine Pollution Buletin 21 (5): 248-253.

Goldberg, E. D. 1986. TBT: An Environment Dilemma. Environment 28; 17-44.

Islami, M. M., 2001. Imposeks Pada Moluska. Oseana , 33 (4), pp. 41-48.

Noor, S. Y., Rumengan, I. F. M., Lasut, M. T., 2013. Pendugaan Pengaruh Bioakumulasi Tributyltin (TBT) Dengan Menggunakan Karakter Imposeks Pada Gastropoda Laut (Thais tuberosa dan Monodonta labio). Journal Aquatic Science \& Management, Vol. 1, No. 1, 5762.

Nuha, U. 2015. Keanekaragaman Gastropoda Pada Lingkungan Terendam ROB Desa Bedono Kecamatan Sayung kabupaten Demak. Skripsi. Fakultas IImu Tarbiyah dan Keguruan Universitas Islam Negeri Walisongo Semarang, 2015.

Pandey, E., Evans, S. M. 1996. The Incidence of Imposex in Gastropods From Indonesian Coastal Waters. Asian Marine Biology, 13, 53-61. 
Rompas, R. M. 1994. Determinasi Logam Berat di Perairan Sulawesi Utara.

Fakultas Perikanan UNSRATMANADO.

Sudaryanto, A. 2001. Pencemaran Laut Oleh Senyawa Organotin. Jurnal Teknologi Lingkungan, Vol. 2, No. 3 241-246.

Svavarsson, J. U. 2000. Imposex in the Dogwhelk (Nucella lapillus) due to TBT Contamination; Improvement at High latitudes. Marine Pollution Buletin. Vol. 40, No. 11, pp 893-897. Institute of Biology, University of Iceland.

Widianwari, P. 2010. Prevelensi Imposeks pada Siput Batu (Thais bitubercularis) Sebagai Indikasi Pencemaran Tributyltin (TBT) di Teluk Jakarta. Jurnal IImu Kelautan Volume 2 Edisi Khusus: $399-414$.

Wagiman, S. 2004. Imposex Dalam Siput Haliah, Thais sp Sebagai Penunjuk Biologi Pencemaran Tributiltimah di Perairan Semenanjung Malaysia. Unpublished Thesis (MSc). Malaysia: Fakultas Kejuruteraan Awam. Universitas Teknologi Malaysia.

Yusuff, M. F., Zulkifli, S. Z., Ismail, A. 2011. Imposex Study on Thais tuberosa from Port and Non Port Areas along the West Coast of Penisular Malaysia. Journal of Tropical Marine Ecosystem, 2: 1-9. 